\title{
Ética e Compromisso Social na Psicologia do Esporte
}

Ethics and social engagement into Sport Psychology

Katia Rubio

Universidade de São Paulo

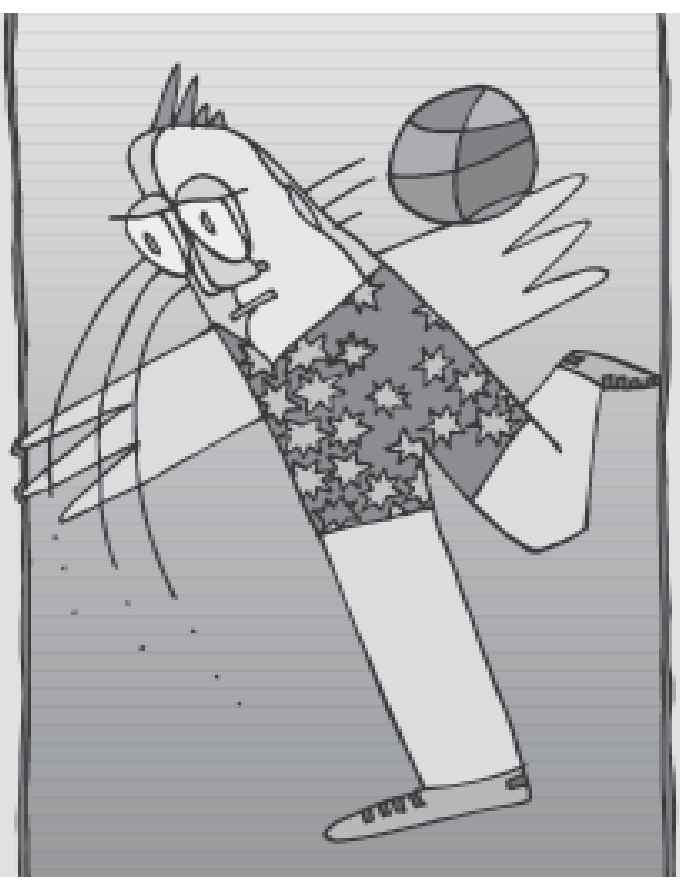




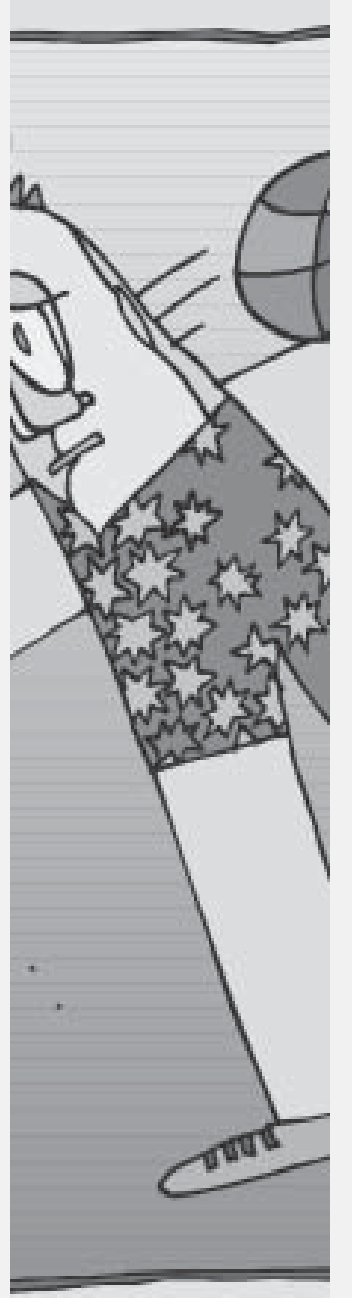

Resumo: A análise do esporte contemporâneo e do papel e da função dos profissionais envolvidos nesse contexto exige uma compreensão da complexa estrutura que levou o espetáculo esportivo a se transformar em um dos principais fenômenos socioculturais contemporâneos. Dentre as muitas questões pertinentes a esse debate, está o limite da busca do rendimento e a relação entre a dimensão do público e do privado na vida dos envolvidos na realização do espetáculo esportivo. A proposta deste ensaio é discutir questões éticas envolvidas na atuação do psicólogo do esporte, apontando a necessidade de superação do entendimento da Psicologia do esporte como uma especialidade que visa apenas e tão somente ao rendimento e à busca da vitória.

Palavras-chave: Psicologia do esporte, Psicologia social do esporte, esporte contemporâneo, cultura e esporte.

Abstract:The contemporary sport and the roll and function of the professionals involved in this context analysis require a comprehension of the complex structure that made the sportive spectacle become the most important contemporary sociocultural phenomenon. Among many important questions in this discussion there is the limit for the performance search and the relation between the public and private dimension in the life of the sportive spectacle protagonists. The purpose of this essay is to discuss the ethic questions involved in the Sport Psychology actuation, pointing the necessity of overcoming the comprehension of Sport Psychology as an specialty that objectives only performance and victory. Key words: Sport Psychology, social Sport Psychology, contemporary sport, culture and sport.

A Psicologia do esporte tem se constituído um desafio para a Psicologia mesmo antes de se tornar uma especialidade. Enquanto área de conhecimento, ela se encontrou, por muito tempo, na divisa entre a Psicologia e a Educação Física, entre os limites do rendimento humano e as atividades motoras básicas e lúdicas. O esporte profissionalizado que ganhou o status de midiático contribuiu muito para uma associação entre a Psicologia e o rendimento esportivo, na medida em que a produção do espetáculo esportivo demanda a utilização de várias especialidades na superação de adversários e recordes, finalidade do esporte competitivo e de pessoas distintamente habilidosas, o atleta de alto rendimento.
Considerada pelos iniciantes como um produto dos anos 80, a Psicologia do esporte tem sua história escrita a partir do início do século XX, na Rússia e nos Estados Unidos, e, mais precisamente, a partir da Copa do Mundo de Futebol de 1958, para o Brasil (Cratty, 1989; Feltz, 1992; McCullagh, 1995; Rubio, 2000). Definida por Williams e Straub (1991, p.30) como a identificação e compreensão de teorias e técnicas psicológicas que podem ser aplicadas ao esporte com o objetivo de maximizar o rendimento e o desenvolvimento pessoal do atleta, ou por Weinberg \& Gould (2001, p.08) como o estudo científico de pessoas no contexto do esporte ou exercício, historicamente a Psicologia do esporte tem se ocupado com programas de treinamento psicológico com o 
objetivo de maximizar o rendimento esportivo. Técnicos, treinadores e atletas buscam conseguir melhor desempenho em competições e aprendem, entre outras coisas, modos de manejo e enfrentamento do stress competitivo, controle da concentração, incremento das habilidades de comunicação e coesão de equipe, o que compõe o chamado esporte de alto rendimento.

Muitos estudos e trabalhos foram produzidos, enfocando, basicamente, a psicometria para a determinação de perfis psicológicos, na busca da relação entre tipo ideal e modalidade ou posição na equipe, ou ainda tipos de intervenção cujo objetivo é a busca da vitória (Cohen, 1976, 1994; Horn, 1992; Landers; Snyder-Bauer; Feltz, 1978; Martens, 1970; Poczwardowski; Sherman; Henschen, 1998; Roberts, 1974; Smith; Smoll; Curtis, 1979;

A Psicologia do esporte tornou-se uma especialidade antes mesmo de ser contemplada como disciplina obrigatória nas grades curriculares dos cursos de graduação em Psicologia no Brasil até poucos anos atrás.
Tenenbaum; Hackfort, 1997).

Todo esse empenho acadêmico e profissional tem levado a Psicologia do esporte a ser identificada com as atividades esportivas competitivas, desprezando outros campos, como as atividades físicas de tempo livre, a iniciação esportiva, a reabilitação de exenfermos ou pessoas portadoras de necessidades especiais, bem como os projetos sociais que têm o esporte como uma atividade meio, e não fim.

Mas essa discussão não se encontra distante de todo o contexto do surgimento e do amadurecimento da área na sua totalidade e enfrenta os desafios da criação de uma identidade e da necessidade de registro das muitas experiências práticas que vão se acumulando como produção de conhecimento.

A Psicologia do esporte tornou-se uma especialidade antes mesmo de ser contemplada como disciplina obrigatória nas grades curriculares dos cursos de graduação em Psicologia no Brasil até poucos anos atrás.
Essa indiferença, no entanto, não é apenas brasileira. Somente em 1986, a Psicologia do esporte foi aprovada pela American Psychological Association como uma de suas divisões, a de número 47 (Feltz, 1992). De acordo com a APA (1999), o interesse dos psicólogos do esporte está voltado para duas áreas: ajudar atletas a fazerem uso de princípios psicológicos para alcançarem um nível ótimo de saúde mental e otimizar sua performance e esclarecer como a participação em atividades físicas e esportivas altera o desenvolvimento psicológico, o bem-estar e a saúde de atletas e não atletas. Nessa perspectiva, fica claro que o trabalho do psicólogo do esporte não se restringe apenas ao esporte de alto rendimento e ao atleta com um alto nível de habilidades motoras.

Por outro lado, a Psicologia do esporte é tida, pela grande maioria dos pesquisadores (Dishman, 1983; Gill, 1986; Morgan, 1989), como uma subárea das ciências do esporte, composta ainda por disciplinas como Antropologia, Filosofia e Sociologia do esporte, no que se refere à área sociocultural, incluindo também a Medicina, a fisiologia e a biomecânica do esporte. Conforme discutido em trabalho anterior (Rubio, 1999), embora as ciências do esporte apresentem uma tendência à interdisciplinaridade, elas ainda estão distantes, porém, de uma prática interdisciplinar, uma vez que as diversas subáreas convivem enquanto soma, mas não em relação.

Essa perspectiva alocou a Psicologia do esporte muito próxima dos estudos experimentais e clínicos, recortando-a do contexto social e cultural maior, o que a distanciou, inclusive, das transformações por que passou o esporte, principalmente o profissionalizado, nas três últimas décadas do século passado. Essas transformações geraram profundas mudanças tanto no comportamento do atleta como na sua relação com as modalidades esportivas, e também com o imaginário social que envolve essa atividade. 
O objetivo deste ensaio é discutir o papel e o lugar da Psicologia do esporte no contexto esportivo atual, considerando as profundas transformações ocorridas nesse cenário ao longo das três últimas décadas do século passado. Isso tem levado a uma reflexão do papel social e profissional de todos os atores envolvidos na preparação e realização do espetáculo esportivo competitivo. Nesse sentido, o psicólogo do esporte, especificamente, se vê envolvido diretamente na relação público-privado que envolve o protagonista do espetáculo esportivo, o atleta e as instituições diretamente envolvidas com essa atividade.

\section{Ética e rendimento esportivo}

O esporte chamado de alto rendimento é um tipo de prática que pode se relacionar ao esporte espetáculo, protagonizado pelo atleta profissional, ou ainda a um tipo de atividade esportiva que não é necessariamente remunerada, mas que exige, do praticante, dedicação e rendimento que superam uma atividade de tempo livre ou amadora.

É no primeiro caso que a Psicologia do esporte tem se apresentado com maior visibilidade, levando-a a ser confundida tão somente com essa perspectiva, isso porque, em busca do rendimento máximo de um atleta, individualmente ou de uma equipe esportiva, são procuradas as variáveis que podem interferir na performance, permitindo que o objetivo maior dessa atividade, ou seja, a vitória, seja alcançada.

Na busca desse objetivo, estão implicados os valores próprios da sociedade atual, como o trabalho alienante, no qual o corpo é usado e manipulado pelo próprio atleta e pela comissão técnica para alcançar o rendimento máximo, em um curto espaço de tempo, atendendo os interesses que gravitam no entorno do espetáculo, como a venda de produtos ou a imagem do patrocinador. Na concretização desse intuito, está envolvida a realização integral do potencial físico e emocional do protagonista do espetáculo esportivo, tendo aqui o psicólogo um papel determinante, uma vez que o rendimento máximo pode estar associado às habilidades e características inerentes do atleta, ou em outra direção, na busca desse maximizador em componentes externos, como o apoio social ou o uso de substâncias proibidas.

Diante dessas questões, o psicólogo se depara com questões relacionadas não apenas à ética profissional mas também à moralidade que circunda o ambiente esportivo.

Ainda que utilizada indiscriminadamente para caracterizar diferentes atitudes, a ética é um preceito que fundamenta vários conceitos. Portanto, não seria viável afirmar uma ética do esporte, uma ética da Psicologia ou quaisquer subéticas para contextos criados conforme a necessidade social ou momento histórico, isso porque a ética busca refletir a respeito das noções e princípios que fundamentam a vida moral. O esporte, enquanto valor cultural, passível da intervenção da Psicologia, também uma criação humana, reflete e recria essa condição. Por isso, é necessário refletir sobre a prática do psicólogo no esporte e qual a sua relação com os valores básicos fundamentais da Psicologia.

A atuação do psicólogo está pautada em um código de ética que é mais que um código de conduta, porque nos fala de um espírito político envolvido na atuação profissional e da responsabilidade que o psicólogo tem com o desenvolvimento da cidadania dos sujeitos e com a promoção da saúde (Luccas, 2000, p. 70). Já o esporte é hoje um fenômeno influenciado por inúmeros interesses, regidos por regras próprias conforme o momento e o lugar onde ele se dá. Isso tem levado, por exemplo, a inúmeras interpretações do conceito de fair play, um tipo de código de ética esportivo não formalizado, e a uma indefinição da melhor conduta esportiva do
A ałuação do psicólogo está pautada em um código de ética que é mais que um código de conduta, porque nos fala de um espírito político envolvido na atuação profissional e da responsabilidade que o psicólogo tem como desenvolvimento da cidadania dos sujeitos e com a promoção da saúde (Luccas, 2000, p. 70). 
Isso quer dizer que é preciso compartilharo conhecimento e os procedimentos psicológicos com os demais membros da equipe

multiprofissional, porém dentro dos limites que resguardem a privacidade de atletas, a comissão técnica e a conduta do psicólogo. atleta tanto em situações de treinos como de competições.

Embora haja flexibilidade naquilo que se refere às normas do esporte contemporâneo, há, por outro lado, uma quase absoluta rigidez nas instituições esportivas que regulamentam e organizam o esporte, tanto em âmbito nacional como mundial. Esse jogo indivíduo/ instituição tem gerado inúmeras interpretações do necessário, do possível e do desejável no ambiente esportivo, demandando, por parte de todos os envolvidos com a área, reflexões sobre ética, tanto em sua dimensão crítica e propositiva quanto em sua dimensão da relação (Guareschi, 2003). A dimensão crítica e propositiva da ética presume a sua incompletude e sua constante atualização, uma permanente busca de crescimento e transformação. A dimensão da relação envolve a discussão do indivíduo na sua interação com o outro.

Essa discussão se torna fundamental diante da dimensão que o esporte adquiriu como fenômeno sociocultural contemporâneo. A necessidade da vitória a qualquer custo, da adequação às mudanças de regras e calendários e os interesses comerciais de clubes e patrocinadores chega ao psicólogo do esporte como um imperativo de sua função no clube ou time, levando-o a uma necessária e constante reflexão sobre seu papel social e profissional, daí a importância da clareza sobre a concepção de ser humano e de Psicologia com que se atua.

Nesse sentido, a orientação do trabalho do psicólogo está dada no Código de Ética Profissional do Psicólogo, em seu Princípio Fundamental I, que afirma: O psicólogo baseará o seu trabalho no respeito à dignidade e à integridade do ser humano, e no Princípio Fundamental VII: O psicólogo, no exercício de sua profissão, completará a definição de suas responsabilidades, direitos e deveres, de acordo com os princípios estabelecidos na Declaração
Universal dos Direitos Humanos, aprovada em 10 de dezembro de 1948, pela Assembléia Geral das Nações Unidas (CRP-SP, 2001, p. 97).

Essas indicações apontam a necessidade de uma prática consciente e crítica da atividade profissional, independentemente do local de sua atuação. O psicólogo vem ocupando, gradativamente, no esporte, espaço em um território dominado historicamente por técnicos, preparadores físicos, médicos, fisioterapeutas, nutricionistas e fisiologistas, constituindo-se em uma atividade multiprofissional por excelência, regulamentada pelos vários códigos profissionais das diversas áreas que compõem a equipe. Ter clareza do que fazer e até onde ir nessas circunstâncias é fundamental para o bom andamento do trabalho do grupo e para uma conduta apropriada (Comissão de Esporte do CRP-SP, 2000).

Isso quer dizer que é preciso compartilhar o conhecimento e os procedimentos psicológicos com os demais membros da equipe multiprofissional, porém dentro dos limites que resguardem a privacidade de atletas, a comissão técnica e a conduta do psicólogo.

Conforme afirma Luccas (2000), a diferença entre o ethos do esporte e da Psicologia é muito grande, e faz parte do trabalho do psicólogo aproximar esses ethos, e não, coadunar com eles. A atenção que o psicólogo atrai sobre seu trabalho possui dois lados distintos e incongruentes: se, por um lado, renova a possibilidade de a Psicologia se aproximar e caminhar junto com o esporte, por outro, o profissional faz uso daquilo que é mais técnico na ciência e na profissão psicológica para praticar uma política do mais insustentável individualismo. Constrói uma prática sem a crítica a si mesma. Segundo o autor, uma prática profissional que não proporcione uma crítica sobre si mesma e não considere o contexto político, social e econômico que envolve o seu objeto de atuação 
não é uma prática ética. Pode ser tecnicamente correta, mas definitivamente está distante de nossa ética (p. 74).

Entretanto, nem todo atleta contemporâneo busca apenas a vitória a qualquer custo. Há praticantes da atividade esportiva que fazem outra opção, originalmente associada ao esporte, que é a superação do próprio limite. Ao conceito que pautava essa prática, era dado o nome de areté, equivalente ao latino virtus, que significava hombridade, valor (Rubio \& Carvalho, 2005). No sentido cavalheiresco da palavra, estava expresso o conjunto de qualidades que fazem do homem um herói, e a vitória seria a confirmação desse valor. A areté seria, portanto, a afirmação da condição pessoal daquele que pratica e vence um desafio; sua realização é a luta contra tudo que tente impedi-la. Essa busca não representa um individualismo egoísta, que cifra ideais de amor a si mesmo, mas a busca incessante pelo absoluto da beleza e do valor, daí a atitude de agradecimento do atleta vencedor de provas atléticas a seus oponentes. Mais do que tê-los como inimigos, o atleta que praticava a areté via, no adversário, o parâmetro para a realização do seu próprio limite, e não alguém a ser superado, vencido e humilhado. O outro era o referencial para a superação de si mesmo.

Ainda que esses valores tenham sido a referência para a reedição dos jogos olímpicos da era moderna e para a institucionalização do esporte contemporâneo, parte deles foi perdido ao longo do século XX ou substituído por apêndices incorporados às novas necessidades desse universo, levando a Psicologia a ser uma ferramenta valiosa nesse contexto.

Cagigal (1996) entendia que a Psicologia do esporte deveria estudar o esporte como um feito humano, ou seja, mais do que se preocupar o com rendimento esportivo, ela deveria promover o desenvolvimento do ser humano por meio do esporte. Aqui o esporte seria um instrumento, um meio para a descoberta e o desenvolvimento de suas potencialidades e habilidades.

\section{Que finalidade teria, então, a preparação e o treinamento psicológicos?}

Quando o lema é rendimento, os esforços são direcionados para a exploração máxima das capacidades individuais e coletivas, para a supressão dos pontos frágeis ou negativos e a maximização daqueles considerados positivos e desejáveis. Nessa situação, não existe qualquer referência à função pedagógica da derrota (Rubio, 2006).

Para tanto, são estudadas as condutas dos praticantes em suas modalidades específicas, buscando-se investigar as relações entre as situações antecedentes e a conduta resultante no âmbito dessa atividade (Balanguer, 1994; Llave, Pérez-Llantada, Buceta, 1999). Para conseguir essa finalidade, a Psicologia busca investigar, com a ajuda de procedimentos objetivos, o funcionamento do comportamento individual e social, a fim de superar as condutas inconscientes, substituindo-as pela observação e a experimentação (González, Rodríguez e García, 2001).

Por outro lado, no entender de Feijó (1992), a preparação psicológica pode ir em uma outra direção. Afirma o autor que os objetivos do preparo psicológico devem coincidir com os objetivos pessoais do atleta, isso porque existem os objetivos políticos e financeiros do clube que está investindo no atleta, os objetivos competitivos de garantir vitórias, os do treinador e outras tantas preocupações dos vários profissionais que compõem a comissão técnica. Sugere o autor que o preparo psicológico do atleta que vive a situação esportiva competitiva deve estar voltado para o equacionamento entre os seus próprios 


\section{É possível afirmar que toda manifestação esportiva é socialmente estruturada, na medida em que 0 esporte revela, em sua organização, no processo de ensino- aprendizageme na sua prática, os valores subjacentes à sociedade na qual ele se manifesta. Questões como o desenvolvimento da identidade do atleta, as formas \\ É possível afirmar que toda manifestação esportiva é socialmente estruturada, na medida em que o esporte revela, em sua organização, no processo de ensino- aprendizagem e na sua prática, os valores subjacentes à sociedade na qual ele se manifesta. Questões como o desenvolvimento da identidade do atleta, as formas de manejo e o controle de concentração e ansiedade, os aspectos de liderança em equipes, estudadas e tratadas de maneira pontual e pragmática dentro da Psicologia do esporte voltada para o rendimento foram deslocadas de um contexto social maior, que é o lugar e o momento que o atleta está vivendo.} de manejo e o controle de concentraçãoe ansiedade, os aspectos de liderança em equipes, estudadas e tratadas de maneira pontual e pragmática dentro da Psicologia do esporte voltada para o rendimento foram deslocadas

de um contexto social maior, que é o lugar e o momento que o atleta está vivendo. interesses e os interesses do complexo esportivo com o qual ele precisa lidar. Muitas vezes, esses interesses convergem para pontos em comum, como o desejo de vitória e de aperfeiçoamento. Entretanto, certas metas são discordantes, como o limite do desgaste do atleta, os prêmios ou a relação treinamento/ lazer, e, nesse universo tão repleto de intenções, o psicólogo acaba por desempenhar o papel de mediador da comunicação dos distintos desejos.

\section{Da Psicologia do esporte à Psicologia social do esporte}

Recentemente alguns estudiosos começaram a repensar a Psicologia do esporte deslocandoa de um modelo de habilidades individuais e passaram a observar a necessidade de uma aproximação com a Psicologia social para a compreensão e explicação desse fenômeno complexo e abrangente que é a atividade física e esportiva (Brawley \& Martin, 1995; Brustad \& Ritter-Taylor, 1997).

Isso só veio reforçar o pressuposto de Lane (1984), o de que toda Psicologia é social, sem que isso signifique reduzir as áreas da Psicologia à Psicologia social. Nesse sentido, é possível afirmar que a Psicologia do esporte, que trata do fenômeno esportivo em toda a sua complexidade, visando à compreensão da dinâmica das relações envolvidas entre atletas, técnicos, dirigentes, mídia e patrocinadores, não é apenas uma Psicologia de rendimento de atletas e equipes, mas uma Psicologia social do esporte.

Ainda que o referencial de Psicologia social utilizado pelos autores norte-americanos esteja baseado em formas psicológicas que reduzem as explicações do coletivo e do social a leis individuais (Bernardes, 1998), é possível avançar essa discussão em direção a uma Psicologia social do esporte, em que se busca situar o atleta e as equipes esportivas coladas à realidade social e cultural vividas (Bock, 2001; Guareschi, Medeiros e Bruschi, 2003).

O debate sobre a função e o papel da Psicologia do esporte passa necessariamente pela discussão do que é o fenômeno esportivo e como tem sido construído e explorado o imaginário esportivo na atualidade. Isso se deve ao fato de o esporte contemporâneo, em seu processo de construção, ter sofrido influência das transformações socioculturais dos diversos momentos históricos pelo qual passou, tendo absorvido, ao longo do século XX, uma série de características da sociedade contemporânea. O que tem sido observado nesse período é que, dentre os vários fenômenos que a sociedade atual vem produzindo, o esporte tem ocupado um dos lugares mais destacados, valorizando a emergência de atitudes heróicas.

Em função disso, características como secularização, igualdade de chances, especialização, racionalização, burocratização, quantificação e busca de recorde, princípios que regem a sociedade capitalista pósindustrial, marcam indelevelmente a prática esportiva, tendo o rendimento como o princípio norteador. No entanto, apontar apenas o rendimento enquanto elemento marcante do esporte contemporâneo, 
apresentado como um dos espetáculos da pósmodernidade, seria desconsiderar outros valores que foram sendo transformados, principalmente a partir da década de 1970, ou, mais precisamente, com a queda em desgraça do conceito de amadorismo.

DaMatta (1994) afirma que a função do esporte no mundo moderno tem uma ligação íntima com dois aspectos fundamentais da vida burguesa: a disciplina - porque ensina e reafirma, nas massas, os limites sociais como regras e deveres - e o fair play - pois o esporte trivializa a vitória e o fracasso, socializa o insucesso e o êxito e banaliza a derrota. Complementando essa idéia, Brohm (1993) entende que o esporte se apresenta como uma preparação da força de trabalho para o trabalho industrial capitalista, uma vez que difunde para os indivíduos, desde muito cedo, o princípio do rendimento e produtividade, fazendo funcionar o corpo de acordo com os princípios tayloristas e implantando uma moral do esforço e do trabalho, o que contribui para a manutenção da exploração de classes. Apesar disso, o esporte se apresenta como politicamente neutro, favorecendo a colaboração de classes, uma vez que expressa a possibilidade do diálogo leal entre os interlocutores (sociais) sob a supervisão de um árbitro imparcial (o Estado).

Para Guttmann (1978), o esporte é uma forma genuína de adaptação à vida moderna e pode ser entendido como um tipo de trabalho disfarçado e desmoralizante. Apresenta, ainda, características como disciplina, autoridade, iniciativa, perfeição, destreza, racionalidade, organização e burocracia, provas do mimetismo e da dependência existentes entre o esporte e o capitalismo industrial.

Conforme Bourdieu (1993), algumas chaves constitutivas do dispositivo esportivo, esboçadas no século XIX, não se transformaram plenamente até meados do presente século. Uma das mudanças mais significativas teve relação com a crescente intervenção do Estado, isso porque a "esportivização" da sociedade constitui uma parte importante da intervenção e do desdobramento de distintas agências que, durante sua atuação, se autodefiniam e se recriavam. Uma outra leitura possível é a de que, desde suas origens, a atividade esportiva de alguma envergadura supõe sempre uma atividade industrial e comercial próxima, que indica que o espaço esportivo foi transformado em um setor da vida econômica e em uma área de consumo muito importante e dinâmica.

Essa condição foi alcançada graças à construção espetacular da narrativa esportiva em que a competição é uma metáfora das batalhas de então, em que adversários reais ou simbólicos serão sempre alvo de superação. Isso quer dizer que a espetacularização do esporte foi construída relacionada ao desenvolvimento da própria prática esportiva e às intervenções e alterações propostas pelos distintos atores envolvidos. Essa narrativa, preocupada em reforçar os aspectos competitivos como igualdade e equilíbrio entre os oponentes, tem reforçado o imaginário da batalha justa, emocionante, de resultado imprevisível, facilitando a emergência de consciências coletivas, identidades nacionais e protagonistas carismáticos e transformando o campo da competição em cenário de representação de atitudes heróicas de atletas que defendem uma equipe, cidade ou país (Rubio, 2001; 2004).

\section{A ética e o fair play}

Se o esporte deve ser entendido como um universo repleto de valores morais, uma vez que, sendo ele uma criação cultural humana, sofreu as transformações próprias do momento histórico em que foi criado, desenvolvido e praticado, mister se faz entender sua dinâmica no âmbito do movimento olímpico para tentar compreender as profundas transformações que ocorreram na sua estrutura, principalmente ao longo do século XX. 
Alguns trabalhos já abordaram esse tema (Rubio, 2000; 2001), porém por uma perspectiva diversa, a do imaginário e da relação próxima com o mito, sem que isso desconsidere valores éticos imprescindíveis para o desenvolvimento do esporte contemporâneo, como o fair play.

O fair play foi utilizado pela primeira vez por Shakespeare, em 1595, sem qualquer relação com a prática esportiva; a partir de 1880, foi incorporado ao esporte para designar um tipo de conduta (Mangan, 1996). Define-se por um conjunto de princípios éticos que orientam a prática esportiva dos atletas e dos demais envolvidos com o espetáculo esportivo (Portela, 1999) e está baseado no ethos cavalheiresco do esporte vitoriano, entendido, em plano mais geral, como uma atitude de prática esportiva moralmente boa e considerado um elemento essencial à realização do potencial educativo dos jogos olímpicos (Tavares, 1999a).

Influenciado pela obra de Hippolyte Taine, Notes sur Anglaterre, e pela metodologia da Rugby School de Thomas Arnold, ou seja, pelo sistema educacional e esportivo inglês, Pierre de Coubertin, o organizador do movimento olímpico contemporâneo, incorporou, ao seu ideário olímpico, a noção do comportamento cavalheiresco no esporte.

O termo fair play compartilha, com o termo olimpismo, a diversidade de interpretação de significados. O senso comum o traduz como 'espírito esportivo' ou 'jogo limpo', sem, com isso, contemplar o cerne da questão, que é a elucidação do conceito. O fair-play presume que haja uma formação ética e moral daquele que pratica e se relaciona com os demais atletas na competição e que esse atleta não fará uso de outros meios que não a própria capacidade para superar os oponentes. Nessas condições, não há espaço para formas ilícitas que objetivem a vitória, o suborno ou o uso de substâncias que aumentem o desempenho (Rubio, 2001).
De acordo com Tavares (1999a), o fair-play, enquanto conjunto de valores normativos do comportamento individual e coletivo no ambiente da competição atlética, reflete a formulação de um ambiente cultural específico, ou seja, por mais que tenha havido uma universalização dos valores esportivos atuais, é preciso contextualizar, do ponto de vista cultural, as transformações que eles sofreram ao longo do século XX, desde que foram formulados por Pierre de Coubertin.

Apesar de amplo e aparentemente irrestrito, o fair-play tem recebido a atenção de estudiosos do olimpismo preocupados com as transformações que vêm ocorrendo nas regras e na conduta dos praticantes das diversas modalidades esportivas, isso porque o próprio movimento olímpico criou padrões, normas e orientações que norteiam e influenciam a prática e o entendimento do esporte, tanto por parte de quem o pratica como de quem o assiste.

Lenk (1986) conceitua o fair-play de duas maneiras: o fair-play formal, que está relacionado diretamente ao cumprimento das regras e dos regulamentos que o participante da competição deve cumprir, em princípio, sendo considerado uma "norma obrigação" (must norm), e o fair-play não formal, que está relacionado ao comportamento pessoal e aos valores morais do atleta e daqueles envolvidos com o mundo esportivo. Não está limitado por regras escritas, e é legitimado culturalmente. A ausência de uma regulamentação oficial confere a ele um caráter subjetivo.

Apesar de caracterizado por uma abordagem normativa e conservadora do comportamento atlético, o fair-play serviu, durante longo tempo, como orientação para os protagonistas do espetáculo esportivo, ainda que não fosse seguido durante todo o tempo.

Assim como o conceito de amadorismo foi abolido ou esquecido pelo olimpismo, 
assistimos a uma mudança no que se refere também ao fair-play. Tavares $(1999 b, 190)$ justifica essa transformação porque $o$ esporte vem sofrendo deslocamentos de sentido nos últimos trinta anos, apontando uma possível relativização dos valores tradicionais ligados à prática esportiva, entre eles, o fair-play.

Tavares tenta justificar essa guinada do olimpismo situando, principalmente, o fair-play dentro de uma nova ordem cultural, sem discutir, entretanto, a motivação intrínseca do olimpismo atual, que está pautado na potência comercial que o COI se tornou. O autor afirma que talvez o próprio conjunto de valores do fair-play necessite ser repensado em função de um cenário cultural bastante diverso do ambiente aristocrático do século passado em que surgiu o olimpismo, incorporando novos valores sociais contemporâneos, ao mesmo tempo que mantendo seus elementos essenciais, numa articulação entre tradição e mudança (p. 190).

Parece acaso, mas o lapso temporal apontado pelo autor coincide com o fim do amadorismo e o início do profissionalismo no esporte, conferindo uma nova moral ao olimpismo.

Partindo da importância que o fenômeno esportivo adquiriu na atualidade, Portela (1999) afirma ser imprudente não considerar o esporte como um dos agentes de formação de códigos éticos e de condutas morais. Sua contribuição para o pensamento e comportamento éticos do indivíduo tornam o fair play o fio condutor da transmissão de valores. Isso quer dizer que o fair play pode ser aceito como a idéia de educar o ser humano para a reciprocidade, no respeito à diversidade humana, desenvolvendo o conceito de semelhança, o que permite a identificação com o outro, a percepção da necessidade do oponente e o entendimento de que o vencedor e o vencido se relacionam a um lapso temporal denominado momento.

\section{Considerações finais}

O esporte contemporâneo surgiu como uma prática aristocrática, cujas regras refletiram, ao longo de muitas décadas, os valores dos grupos hegemônicos que ditaram os rumos das instituições esportivas em nível nacional e internacional.

As transformações por que passou a sociedade ao longo do século XX imprimiram profundas mudanças tanto no ideário olímpico, que tem norteado grande parte da estrutura esportiva, como na organização das instituições esportivas que viabilizam esse ideário. Uma das principais alterações que se pode aqui citar é o abandono do amadorismo, valor considerado basilar da gênese do olimpismo, em prol do profissionalismo, defendido como condição sine qua non para a sobrevivência do esporte competitivo.

Os efeitos dessa mudança podem ser percebidos em muitas dimensões, tanto de ordem objetiva (contratos de patrocínio, salários, ampliação do mercado de trabalho das várias áreas envolvidas direta ou indiretamente com a realização do espetáculo esportivo) como de ordem subjetiva (a construção da identidade do atleta, os efeitos da exposição pública de seu mundo privado, a visibilidade excessiva e o ostracismo precoce).

É nesse ambiente complexo que o psicólogo do esporte tem sido chamado a atuar. Isso significa dizer que, embora seu objetivo final seja uma atuação junto ao atleta, outros elementos que estão interagindo ou influenciando sua vida precisam ser considerados e pautados nessa intervenção, ou seja, é cada vez maior a pressão dos fatores externos exercida sobre a atividade profissional tanto do atleta como dos profissionais que compõem a equipe que atua junto a ele. Nesse sentido, torna-se imprescindível uma análise em nível macro (instituição e grupo esportivo) e micro (o atleta) para se organizar um planejamento (periodização) da intervenção psicológica, sem ferir os preceitos básicos que norteiam a prática profissional do psicólogo.
Partindo da importância que o fenômeno esportivo adquiriu na atualidade, Portela(1999) afirma ser imprudente não considerar o esporte como um dos agentes de formação de códigos éticos e de condutas morais. 


\section{Katia Rubio}

Escola de Educação Física e Esporte da Universidade de São Paulo

Rua Doralice Paixão Teixeira, 76, ap. 11

Vila Madalena

São Paulo - SP

CEP 05417-070

AMERICAN PSYCHOLOGICAL ASSOCIATION How can a psychologist become a sport psychologist? http:// www.psyc.unt.edu/apadiv47, 1999.

BALAGUER, I. Entrenamiento Psicológico en el Deporte. Valencia: Albatros, 1994.

BERNARDES, J. S. História. In: Jacques, M.G.C.; Strey, M.N.; Bernardes, M.G.; Guareschi, P.A.; Carlos, S.A.; Fonseca,T.M.G. (orgs.) Psicologia Social Contemporânea: Livro-texto. Petrópolis: Vozes, 1998.

BOCK, A. M. B. A Psicologia Sociohistórica: uma Perspectiva Crítica em Psicologia. In: Bock, A. M. B.; Gonçalves, M.G.M.; Furtado, O. (orgs.) Psicologia Sociohistórica: uma Perspectiva Crítica em Psicologia. São Paulo: Cortez, 2001.

BOURDIEU, P. Deporte y Classes Sociales. In.: Gonzalez, J.I.B. Materiales de Sociologia del Deporte. Madrid: Las Ediciones de La Piqueta, 1993.
BRAWLEY, L. R. \& MARTIN, K. A. The Interface between Social and Sport Psychology. The Sport Psychologist., Sheffield, 9, , pp.469497, 1995.

BROHM, J. M. 20 Tesis sobre el Deporte. In.: Gonzalez, J.I.B.. Materiales de Sociologia del Deporte. Madrid: Las Ediciones de La Piqueta, 1993.

BRUSTAD, R. J. \& RITTER-TAYLOR, M. Applying Social Psychological Perspectives to the Sport Psychology Consulting Process. The Sport Psychologist, Sheffield,11, pp.107-119, 1997.

CAGIGAL, J. M. Obras Selectas V. II. Madrid: Comité Olímpico Español/Consejo Superior de Deportes, 1996.

COHEN, L. H. Clinicians' Utilization of Research Findings. JSAS Catalog of Selected Documents in Psychology, Washington D.C., 6, p.116, 1976. 
COHEN, J. The Earth is Round ( $\mathrm{p}<.05)$. American Psychologist, 49 , pp.997-1003, 1994

COMISSÃO DE ESPORTE DO CONSELHO REGIONAL DE PSICOLOGIA DE SÃO PAULO. A Avaliação Psicológica no Esporte ou os Perigos da Normatização e da Normalização. In: Rubio, K.org. Psicologia do Esporte: Interfaces, Pesquisa e Intervenção. São Paulo: Casa do Psicólogo, 2000

CONSELHO REGIONAL DE PSICOLOGIA DE SÃO PAULO. Manual do Conselho Regional de Psicologia SP. São Paulo, 2001.

CRATTY, B. J. Psychology in Contemporary Sport. Englewood Cliffs: Prentice Hall, 1989.

DaMATTA, R. Antropologia do Óbvio. Notas em Torno do Significado Social do Futebol Brasileiro. Revista USP. Dossiê Futebol, São Paulo, n. 22, pp. 10-17, jun-ago. 1994

DISHMAN, R. K. Contemporary Sport Psychology. In: Terjung, R.L. (ed.) Exercise and Sport Sciences Reviews. Philadelphia: Franklin Institute Press, 1982.

FEIJÓ, O. Corpo e Movimento. Uma Psicologia para o Esporte. Rio de Janeiro: Shape, 1992.

FELTZ, D. L. The Nature of Sport Psychology. In: Horn, T. S.(ed.) Advances in Sport Psychology. Champaign(Illinois): Human Kinetics, 1992.

GILL, D. L. The Prediction of Group Motor Performance from Individual Member Abilities. Journal of Motor Behavior, Washington D.C., 11 pp.113-122, 1979.

Human Kinetics, 1986.

Psychological Dynamics of Sport. Champaign(Illinois):

GONZÁLEZ, J. L.; RODRÍGUEZ, C. G.; GARCÍA, G. M. Manual de Prácticas de Psicología Deportiva. Madrid: Biblioteca Nueva, 2001.

GUARESCHI, P. A. Ética e paradigmas. In: Ploner, K.S.; Michels, L.R.F.; Schlindwein, L.M.; P.A.Guareschi (orgs.). Ética e Paradigmas na Psicologia Social. Porto Alegre: ABRAPSOSUL, 2003.

GUARESCHI, N. M. F.; MEDEIROS, P. F.; BRUSCHI, M. E. Psicologia Social e Estudos Culturais: Rompendo Fronteiras na Produção do Conhecimento. In: Guareschi, N.M.F., e Bruschi,M.E. (orgs). Psicologia Social nos Estudos Culturais. Petrópolis: Vozes, 2003.

GUTTMANN, A. From Ritual to Record. New York: Columbia University Press, 1978.

HORN, R. S. Advances in Sport Psychology. Champaign: Human Kinetics, 1992.

JAMESON, F. Pós-modernismo. A Lógica Cultural do Capitalismo Tardio. São Paulo: Ática, 1999.

LANDERS, D. M.; SNYDER-BAUER, R.; FELTZ, D. L. Social Facilitation during the Initial Stage of Motor Learning: a Re-examination of Martens' Audience Study. Journal of Motor Behavior, Washington D.C., 10, pp.325-337, 1978.

LANE, S. A Psicologia Social e uma Nova Concepção de Homem para a Psicologia. In: Lane, S. \& Codo, W. (orgs). Psicologia Social: o Homem em Movimento. São Paulo: Brasiliense, 1984.

LLAVE, A. L.; PÉREZ-LLANTADA, M. C.; BUCETA, J. M Investigaciones Breves en Psicología del Deporte. Madrid: Dykinson, 1999.

LUCCAS, A. N. A Psicologia, o Esporte e a Ética. In: Rubio, K., org. Encontros e Desencontros: Descobrindo a Psicologia do Esporte São Paulo: Casa do Psicólogo, 2000.

MARTENS, R. A Social Psychology of Physical Activity. Quest Knoxville,14, pp.8-17, 1970
MANGAN, J. A. Muscular, Militaristic and Manly: the British Middleclass Hero as Moral Messenger. In: Holt, R.; Mangan, J.A.; Lanfranchi, P. European Heroes: Myth, Identity, Sport. London: Frank Cass, 1996.

McCULLAGH, P. Sport Psychology: a Historical Perspective. The Sport Psychologist. Sheffield, 9, pp.363-365, 1995.

MORGAN, W. P. Sport Psychology in its own Context: a Recommendation for the Future. In: Skinner,J.S.; Corbin, C.B. Landers, D.M.; Martin, P.E. \& Wells, C.L. (eds.). Future Directions in Exercise and Sport Sciences Research. Champaign: Human Kinetics, 1989.

POCZWARDOWSKI, A; SHERMAN, C. P.; HENSCHEN, K. P. A Sport Psychology Service Delivery Heuristic: Building on Theory and Practice. The Sport Psychologist., Sheffield,12, pp.191-207, 1998.

PORTELA, F. Contrapondo Teorias da Formação Ética e a Prática do Fair Play. In: Tavares, O.; DaCosta, L.P., eds. Estudos Olímpicos. Rio de Janeiro: Editora Gama Filho, 1999.

ROBERTS, C. G. Effect of Achievement Motivation and Socia Environment on Risk Taking. Research Quarterly, Danvers, 45, pp.4255,1974

RUBIO, K. Psicologia do Esporte: Histórico e Áreas de Atuação e Pesquisa. Psicologia: Ciência e Profissão, Brasília, 19 (3), pp.60-69, 1999.

RUBIO, K. O Trajeto da Psicologia do Esporte e a Formação de um Campo Profissional. In: Rubio, K. (org.). Psicologia do Esporte Interfaces, Pesquisa e Intervenção. São Paulo: Casa do Psicólogo, 2000.

O Atleta Contemporâneo e o Mito do Herói. São Paulo: Casa do Psicólogo, 2001.

Heróis Olímpicos Brasileiros. São Paulo: Zouk, 2004.

Medalhistas Olímpicos Brasileiros: Memórias, Histórias e Imaginário. São Paulo: Casa do Psicólogo, 2006.

RUBIO, K.; CARVALHO, A. L. Areté, Fair Play e o Movimento Olímpico Contemporâneo. Revista Portuguesa de Ciências do Desporto, Porto, v. 03, pp. 350-357, 2005

SMITH, R. E.; SMOLL, F. L.; CURTIS, B. Coach Effectiveness Training: a Cognitive-behavioral Approach to Enhancing Relationship Skills in Youth Sport Coaches. Journal of Sport Psychology, Champaing, 1, pp. $59-75,1979$.

TENENBAUM, G.; HACKFORT, D. ISSP, NHST and IISP: Unrelated Events? International Journal of Sport Psychology, Porto, 28, pp.307-308, 1997.

TAVARES, O. Referências Teórias para o Conceito de 'Olimpismo'. In: Tavares, O.; DaCosta, L.P., eds. Estudos Olímpicos. Rio de Janeiro: Editora Gama Filho, 1999.

Algumas Reflexões para uma Rediscussão do FairPlay. In: Tavares, O. \& DaCosta, L.P. (eds.) Estudos Olímpicos. Rio de Janeiro: Editora Gama Filho, 1999. b.

WEINBERG, R. S.; GOULD, D. Fundamentos da Psicologia do Esporte e do Exercício. Porto Alegre: Artmed Editora, 2001.

WILLIANS, J. M.; STRAUB, W. F. Nueva Psicologia del Deporte: Pasado, Presente, Futuro. In: Willians, J.M. (org.). Psicologia Aplicada al Deporte. Madrid: Biblioteca, 1991. 